\title{
Endoscopical Polypectomy of the Gastric Polyp with Electro-Coagulation Wire Loop
}

\author{
Saburo Oshiba, Kotaro Ueno, Fukuji Mochizuki, Shigeru \\ Asaki, Shorchiro Ito, Toru Yanbe and Shoichi Yamagata \\ The Third Department of Internal Medicine, Tohoku University \\ School of Medicine, Sendai
}

\begin{abstract}
Oshrba, S., Ueno, K., Mochlzuki, F., Asaki, S., Ito, S., Yanbe, T. and Yamagata, S. Endoscopical Polypectomy of the Gastric Polyp with ElectroCoagulation Wire Loop. Tohoku J. exp. Med., 1976, 118 (Suppl.), 53-59 A forward-viewing fiberscope equipped with two channels was designed for safer and easier gastric polypectomy under endoscopic control using electro-surgical technique. No electrical accident, bleeding, perforation or significant complications were noticed. Mucosal ulcerations at the polypectomy site healed within a month leaving minor scars behind. In 30 cases, UI II gastric ulcers developed after polypectomy, which healed leaving convergence of mucosal folds behind. Fiberscopic excision of gastric polyps was also useful for establishing a reliable diagnosis of gastric polyp cancer which is sometimes overlooked by routine biopsy procedure. It may be the "perfect biopsy". The patient with gastric polyp who is aware of his own illness and feels uneasy can be released from his anxiety and regain both physical and mental health at the cost of minimal risk of endoscopic polypectomy. polyp; polypectomy; electrocoagulation
\end{abstract}

The conventional excision of the gastric polyp by gastrectomy or gastrotomic polypectomy causes severe insults to patients, while endoscopic polypectomy proved to be an excellent therapeutic measure for the gastric polyp only if it can be performed safely because it gives less insults.

For the purpose of non-surgical removal of gastric polyp, Uchida et al. (1969) proposed polypectomy under direct observation through a fiberscope. The method was successful in excision of the polyp by strangulating its base with a wire loop through the channel for bioptic forceps of fiberscope. This technique can be applied for polyps of type IV and III by Yamada's classification (1966), but is accompanied by hemorrhage due to mechanical severance of the nutritive blood vessel that runs through the peduncle of the polyps. It is associated with a risk of massive hemorrhage following the excision of polyp.

Then, in order to prevent hemorrhage at excision of the gastric polyp, to ensure safe excision of thickly pedunculated polyps or type II polyps and to carry out infallibly the histopathologic examination of the collected polyps, a method has been developed at our laboratory, in which the peduncle of polyp was coagulated with a snare to which a high frequency electric current was applied. With this method bleeding was effectively avoided.

Received for publication, November $20,1975$. 
Clinical trials were made with a new forward-viewing fiberscope developed in our laboratory which is slenderer than the conventional fiberscope and has two channels so as to facilitate excision and collection of the gastric polyp and to lessen distress to the patient, and the findings obtained are presented in the present report.

\section{INSTRUMENT}

Fiberscope used was a P.F.S.-Type F equipped with two channels, which was experimentally made by Machida Co., Ltd. Metallic portion of the fiberscope was covered with rubber so as to prevent an electrical accident (Fig. 1). The diameter of the channel is $2.8 \mathrm{~mm}$ and is larger than that of the ordinary type fiberscope (Fig. 2).

One of the channels was used for the passage of the wireloop covered with Teflon tube for polypectomy. The other channel was for the insertion of pick-up forceps by which the tip of the polyp will be grasped, a polyp will be hung into the wire loop and will be collected at the time of resection. High frequency coagulation unit manufactured by Machida Co., Ltd. was a spark gap type with 48 Watts at its maximum power and 2.5 $\mathrm{MHz}$ of its central frequency. The dial calibration of ten graduating series regulates the power and sends $300 \mathrm{~mA}$ of currents to the wire loop. The coagulation unit is also

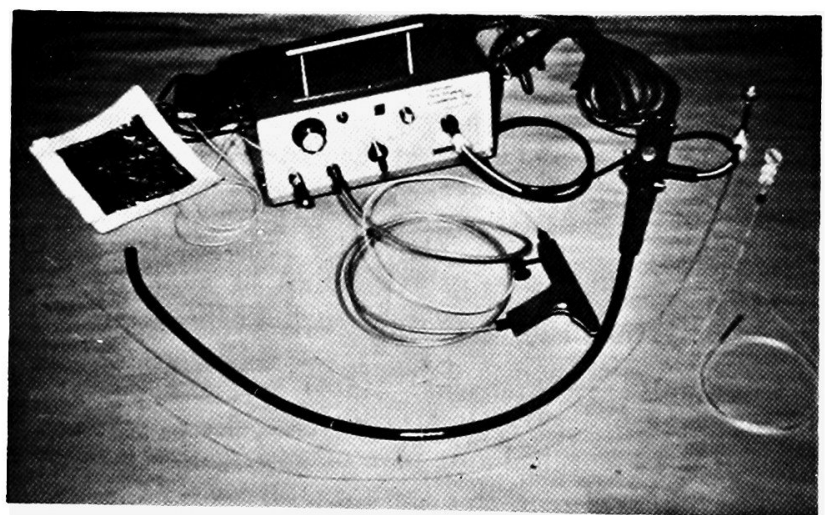

Fig. 1. Instrument.

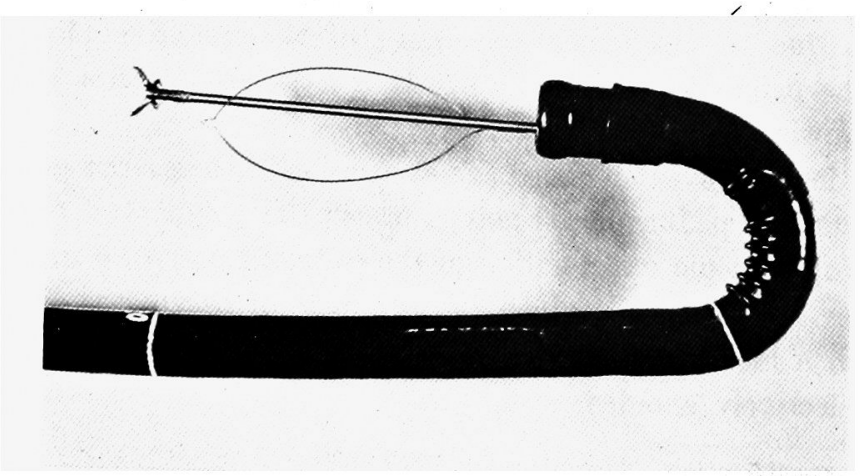

Fig. 2. Tip of two-channels-front-view-fiberscope. 


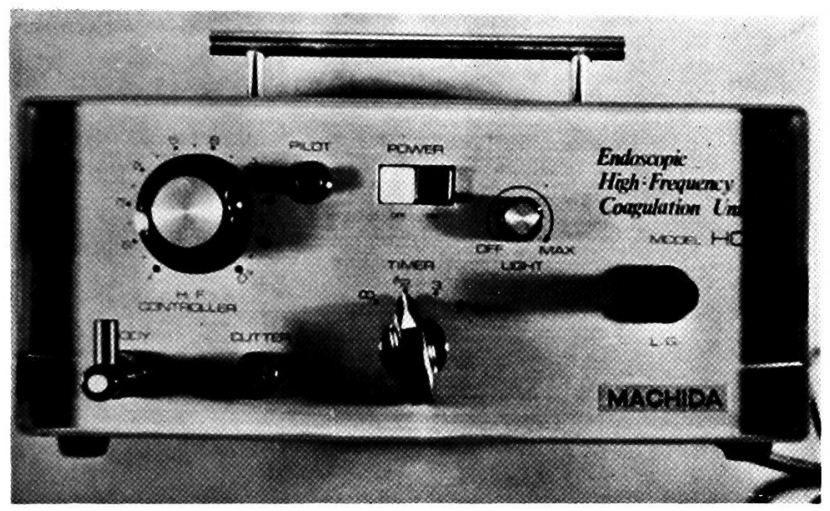

Fig. 3. Endoscopic high-frequency coagulation unit.

equipped with light source and a time regulator for easier control, and the optimal power and time were set depending on the size of polyp and thickness of the pedicle (Fig. 3).

Prior to polypectomy all patients were examined for hemorrhagic tendency. Biopsy can be performed to obtain preliminary histological information. A sufficient amount of antispasmodica is given to control the gastric motility during the procedure.

\section{Procedure}

The procedure starts in the same manner as with the usual forward-viewing fiberscopy. The polyp being reidentified in the stomach, the grasping forceps is passed through a channel until its tip gets within the sight. Then the electrosurgical snare device is passed through the other channel to form a loop at its end which is pushed towards the gastric wall and the grasping forceps is sent forward to pass (Fig. 4a). The snare device is then withdrawn up to the tip of fiberscope while holding the forceps inside.

In the next step the fiberscope can be moved on to the polyp, which is grasped and pulled by the forceps (Fig. 4b). The snare inside the Teflon sheath is then advanced to catch the polyp and gradually closed around its base (Fig. $4 \mathrm{c}, \mathrm{d}$ ). When the snare fully holds the base of the polyp, electric currents are applied (Fig. 4e). Power and time settings on the coagulation unit are adjusted for each individual polyp depending on the thickness of pedicle.

When coagulation and cutting are completed, the resected end of the polyp in gastric mucosa should carefully be examined for bleeding, while the excised polyp is being grasped by the forceps. The forceps is then withdrawn against the tip of the scope which is gradually removed with suction to collect the excised polyp (Fig. 4f).

\section{RESULTS}

By August 1974, polypectomy had been performed for 125 polyps in 100 patients in our clinic. Cautery with a high frequency rod was performed for ten fine polypoid lesions. The 100 patients consisted of 48 men and 52 women, ranging in age from 33 to 76 years. Out of 135 polyps, $77(57 \%)$ were located in $\mathrm{A}, 45(33 \%)$ in $\mathrm{M}$, and $13(10 \%)$ in $\mathrm{C}$ by the C.M.A. classification determined by Japanese Society For Gastric Cancer Research, that is, the polyps located in A accounted for the majority (Table 1). By Yamada's classification, $12(9 \%)$ were of type I, $24(18 \%)$ of type II, $32(24 \%)$ of type III, and $67(50 \%)$ of type IV, 
a
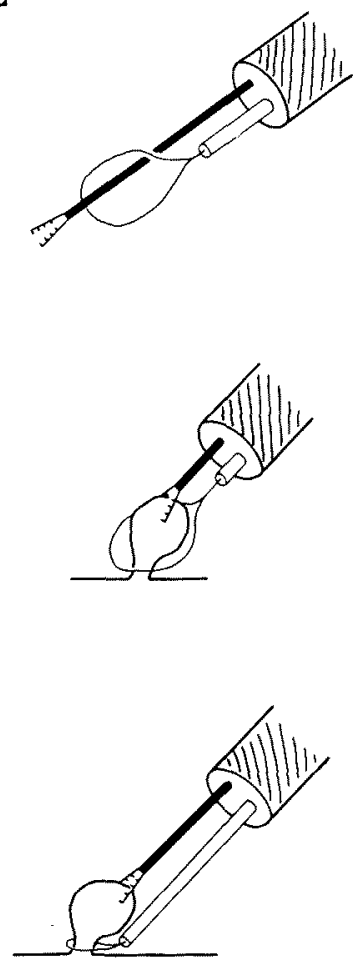

b

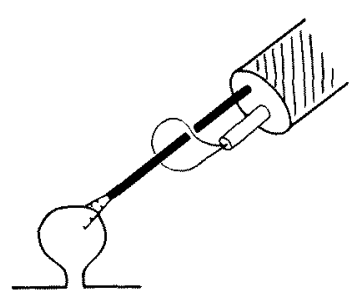

d


Fig. 4. The procedure of polypectomy is shown in Figs. a-f.

Fig. (a) shows that the electrosurgical snare device is passed through the other channel to form a loop at its end. Fig. (b) shows that polyp is grasped and pulled by the forceps. It is shown that the snare catches the polyp and closes around the base of the polyp in Figs. (c) and (d). Fig. (e) shows the snare fully holding the base of the polyp. Fig. (f) shows the forceps withdrawn against the tip of the scope.

TABLE 1. Location of polypoid lesions

\begin{tabular}{ccccc}
\hline Location & A & M & C & Total \\
\hline $\begin{array}{c}\text { Number of cases } \\
(\%)\end{array}$ & $\begin{array}{c}77 \\
(57.0)\end{array}$ & $\begin{array}{c}45 \\
(33.3)\end{array}$ & $\begin{array}{c}13 \\
(9.7)\end{array}$ & 135 \\
\hline
\end{tabular}

For $\mathrm{A}, \mathrm{M}$ and $\mathrm{C}$ in the table refer to the attached diagram.

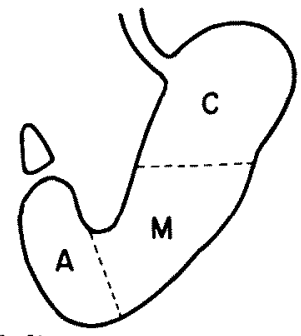

that is, polyps of type IV accounted for the largest part of 135 polyps (Table 2).

Out of 125 excised polyps, 120 were successfully collected, with a collection rate of $96 \%$ (Table 3 ). The other five polyps could not be collected due to unskillfulness in the early stage of the trials and mechanical troubles of the grasping forceps. Recently, excised polyps are successfully collected in almost all cases. 
TABLE 2. Type of polypoid lesions

\begin{tabular}{|c|c|c|c|c|c|}
\hline Tyne & I & II & III & & \\
\hline $\begin{array}{c}\text { Number of cases } \\
(\%)\end{array}$ & $\begin{array}{l}12 \\
(8.9)\end{array}$ & $\begin{array}{c}24 \\
(17.8)\end{array}$ & $\begin{array}{c}23 \\
(23.7)\end{array}$ & $\begin{array}{c}67 \\
(49.6)\end{array}$ & 135 \\
\hline
\end{tabular}

TABLE 3. Percentage of collection of resected polyp

\begin{tabular}{lccc}
\hline & $\begin{array}{c}\text { Number of } \\
\text { cases }\end{array}$ & $\begin{array}{c}\text { Successful } \\
(\%)\end{array}$ & $\begin{array}{c}\text { Unsuccessful } \\
(\%)\end{array}$ \\
\hline Polypectomy & 125 & 120 & 5 \\
Cautery & 10 & $(96.0)$ & $(4 \%)$ \\
\hline
\end{tabular}

There were two polyps that could be excised merely by strangulating with the snare without application of high frequency electric current. Both of them were small pedunculated polyps of type IV with slender peduncles. The excision was accompanied only by such a degree of hemorrhage which is seen in common biopsy; however, no ulceration followed polypectomy, and excision wounds were healed rapidly and ran favorable courses.

Excision of all of 123 polyps by application of electric current was followed by ulceration due to the cautery. In 30 polyps, convergence of mucosal folds remained after the ulcers had been healed, and these were polyps with thick peduncles or unpedunculated polyps.

The courses of the cautery ulcers formed by the application of electric current were as follows: White coat disappeared within three weeks in 69 out of 120 polyp sites ( $58 \%$ of cases), remained for more than three weeks in 51 polyp sites (42\% of cases), and remained for more than one month in only few polyp sites (Table 4). The follow-up observation has revealed no recurrence of any one of the polyps.

Patients with both gastric polyp and gastric cancer received gastrectomy after polypectomy. Histologic examination proved that all cautery ulcers were of the depth of U1 II.

Excision of 96 polyps out of the 135 (71\% of cases) was not accompanied by hemorrhage at all. Out of 39 polyps accompanied by hemorrhage, $23(17 \%)$ caused only oozing hemorrhage; in $14(10 \%)$ the severity of hemorrhage was comparable with that at biopsy; and none induced massive hemorrhage. Attention

TABLE 4. Time of disappearance of white coat after polypectomy

\begin{tabular}{ccc} 
& Within 3 weeks & More than 3 weeks \\
\hline Polypectomy & 69 & 51 \\
$(\%)$ & $(58.0)$ & $(42.0)$ \\
Cautery & 9 & 1 \\
\hline
\end{tabular}


S. Oshiba et al.

TABLE 5. Degree of bleeding after polypectomy

\begin{tabular}{|c|c|c|c|c|c|c|}
\hline \multirow{2}{*}{$\begin{array}{l}\text { Degree of } \\
\text { bleeding }\end{array}$} & \multirow{2}{*}{$\begin{array}{l}\text { Number of } \\
\text { cases }\end{array}$} & \multicolumn{5}{|c|}{ Time intervals following polypectomy } \\
\hline & & Immediate & $4 \mathrm{hr}$ & $24 \mathrm{hr}$ & $48 \mathrm{hr}$ & $72 \mathrm{hr}$ \\
\hline No bleeding & 96 & & & & & \\
\hline Oozing & 23 & 15 & 6 & 2 & & \\
\hline Mild & 14 & 11 & 1 & & & \\
\hline Moderate & 2 & 1 & 1 & & & \\
\hline Massive & 0 & & & & & \\
\hline
\end{tabular}

TABLE 6. Comparison of histologic diagnosis between gastric biopsy and removed polyp

\begin{tabular}{|c|c|c|c|c|c|c|}
\hline \multirow[b]{2}{*}{ Biopsy } & \multicolumn{6}{|c|}{ Removed polyp } \\
\hline & $\begin{array}{c}\text { Foveolar } \\
\text { hyperplasia }\end{array}$ & $\begin{array}{l}\text { Hyperplastic } \\
\text { polyp }\end{array}$ & $\begin{array}{l}\text { Atypical } \\
\text { epithelium }\end{array}$ & Cancer & $\begin{array}{l}\text { Diagnosis } \\
\text { impossible }\end{array}$ & Total \\
\hline $\begin{array}{l}\text { Foveolar } \\
\text { hyperplasia }\end{array}$ & $19(68 \%)$ & 5 & & & 4 & 28 \\
\hline $\begin{array}{l}\text { Hyperplastic } \\
\text { polyp }\end{array}$ & 5 & $80(9296)$ & & 1 & 1 & 87 \\
\hline $\begin{array}{l}\text { Atypical } \\
\text { epithelium }\end{array}$ & & & 2 & 1 & 1 & 4 \\
\hline $\begin{array}{l}\text { Suspected } \\
\text { cancer }\end{array}$ & & & 1 & & & 1 \\
\hline Total & 24 & 85 & 3 & 2 & 6 & 120 \\
\hline
\end{tabular}

should, however, be called for to the findings that the mild hemorrhage was seen in eight polyps four hr after operation, in two $24 \mathrm{hr}$ after operation, in one $48 \mathrm{hr}$ after operation and also in one $72 \mathrm{hr}$ after operation (Table 5).

The wound surface was observed four $\mathrm{hr}, 24 \mathrm{hr}$, two days, four days, one week after excision of the gastric polyp, and once every week thereafter, and further once a month after disappearance of white coat.

Histopathologic findings of the 120 polyps collected were compared with those of biopsied materials of the polyps before polypectomy. In 28 polyps with bioptical diagnosis of foveolar hyperplasia, $19(68 \%)$ had also foveolar hyperplasia in postoperative histologic examination, and five was diagnosed as hyperplastic polyp. In 87 polyps with bioptical diagnosis of hyperplastic polyp, the diagnosis was confirmed by postoperative histologic examination in $80(92 \%)$. There was, however, one polyp in which cancer was detected by histologic examination on its serial sections. Further, out of four polyps which showed atypical epithelial cells at biopsy, one was diagnosed as cancer in postoperative histologic examination. In one polyp, cancer was suspected at biopsy but postoperative histologic examination revealed only atypical epithelial cells.

\section{Disscussion}

Gastric polyp has been regarded as one of the grounds where gastric cancer develops and it has been considered that cancerization of polyp is not rare. 
For this reason, gastrectomy has been the therapy which should be performed when the diagnosis of gastric polyp was established. Recent follow-up studies of gastric polyps revealed that cancerization is very rare, although they may be markedly enlarged or deformed during a period of five to ten years (Ueno and Oshiba 1973). Therefore, it is a common conclusion that gastric polyp bioptically diagnosed as benign should only be kept under observation. It is, however, undeniable that a patient with polyp wishes to have it excised, so that he can be relieved of such a mental stress that he has a polyp in his stomach and he can also be relieved from troubles of periodical examination. Endoscopical polypectomy of gastric polyp finds its clinical significance in this respect. In other words, it is desirable to excise gastric polyp by non-blood-shedding-measures with only very slight insult and distress. The technique described in the present report causes only slight intra-operative and postoperative hemorrhages, and the ulcers caused by cauterization are cicatrized in one month in almost all cases (Oguro 1974). It takes only ten to $20 \mathrm{~min}$ to excise and collect a polyp.

What is more important is the limited reliability of bioptic diagnosis (Seifert and Elster 1972). Because almost all polyp cancers are of such a type that cancer exists at the top of the polypoid structure, the diagnostic accuracy of biopsy is poor when only the oral side of polyps can be biopsied. It is also impossible in biopsy to obtain specimens from all parts of the surface of a polyp. For this reason, benignancy concluded from biopsy specimens does not entirely rule out malignancy. Because polypectomy completely excises a polyp from its base, it may be called a complete biopsy. Out of the polyps that had been bioptically diagnosed as hyperplastic polyp in our clinic, one proved to be cancer, and cancer was found in one of the polyps that had been considered to have atypical epithelial cells. On the other hand, a polyp which had been strongly suspected of cancer at biopsy proved to have only atypical epithelial cells. The disagreement in the results of the two methods is of clinical importance.

\section{References}

1) Oguro, Y. (1974) Endoscopic gastric polypectomy with high frequency curreats. Stomach and Intestine (Jap.), 9, 309-316.

2) Seifert, E. \& Elster, K. (1972) Endoscopische Polypektomie an Magen; Indikation, Technik und Ergebnisse. Deut. med. Wshr., 97, 1199-1203.

3) Uchida, T., Tsuneoka, K., Watanabe, N., Kobayashi, M., Kasugai, K., Katsuta, N., Komine, S. \& Saito, K. (1969) The technique and significance of our endoscopic polypectomy. Jap. J. Gastroent., 66, 1027-1028.

4) Ueno, K. \& Oshiba, S. (1973) Clinical observation on polypoid lesion of the stomach. The 1st Asian-Pacific Congress of Endoscopy, 152-154.

5) Yamada, T. \& Hukutomi, H. (1966) Polypoid lesion of the stomach. Stomach and Intestine (Jap.), 1, 145-150. 